\title{
Clinical management of chemotherapy in geriatric patients
}

\begin{abstract}
Goal: To describe the clinical management of chemotherapy in geriatric patients carried out by nurses of a hospital accredited at the level of excellence in Brazil.

Methods: This is a descriptive study of a qualitative nature, of the type of experience report, about the clinical management of chemotherapy in geriatric patients performed by Nurses.

Results: There are three nuclei of meaning for a better interpretation and perspective of the study "Nursing Assistance in Geriatric Oncology "," Clinical Management of Chemotherapy Performed by Nurses" AND "Nurses' Performance in an Accredited Hospital at the Excellence Level in Brazil”.

Conclusion: It is pointed out that the nurses of the service are able to carry out the clinical management of chemotherapy in geriatric patients, regarding the availability of materials and equipment of quality of the service, as a facilitating tool in the care process.
\end{abstract}

Keywords: clinical management, chemotherapy, geriatric nursing, oncology nursing
Volume 3 Issue 5 - 2018

\author{
Lima MCSC, Asevio CNV, Edienne Rosângela \\ Sarmento Diniz, Sheila Duarte de Mendonça \\ Fernandes, Aurora Tatiana Soares da Rocha, \\ Gabriele Maria Dantas Diniz, Ailza Roque \\ de Brito, Luciana Lays Vieira Rolim, Maria \\ do Livramento Silva Bitencourt, Rafaela \\ Fernandes de Carvalho \\ Master of Nursing, Federal University of Pernambuco, Brazil
}

Correspondence: Lima MCSC, Master of Nursing, Federal University of Pernambuco, Brazil,

Email enfermeiros_unimed@outlook.com.br

Received: October 04, 2018 | Published: October 15, 2018

\section{Introduction}

At the present time, cancer is still a morbidity surrounded by stigma, and is almost always associated with a death sentence, being considered, today, the second cause of death in developed countries and the fifth in Brazil. It is estimated that approximately 554 thousand new cases of cancer occur every year. ${ }^{1}$

In this respect, this pathology has been considered as an irreversible process presenting different meanings, both for the nurse and for the patient, established according to their socio-cultural experiences, legends, fears, and uncertainties, from the moment the possibility, even if remote, from its diagnosis. Culturally, the stigma of death is related to cancer, manifesting itself with characteristics in the patientteam relationship. ${ }^{2}$

By a cultural inheritance or even personal formation, each human being carries within himself this individual representation of death, to which are attributed influences of the social life, means of communication and peculiarities of each individual that contribute to its mystification. ${ }^{3}$

The nursing professional is the person who is closest to the patient in difficult times and is the one the patient and the family seeks when they need explanations or immediate care. It should be seen that the nurse needs to understand and deal with the feelings that the oncological disease causes such as the suffering, anguish, fears that may arise in situations involving this care. This care presupposes knowing not only the pathology, but knowing how to deal with the feelings of others, as with one's own emotions in the face of disease, with or without the possibility of a cure. ${ }^{4}$

This situation can be found in several studies currently carried out with nurses, for example, in order to know the impact that care to the cancer patient with imminent death possibility can promote in the nursing team that is fragile and experiencing emotional pressure for their beliefs and values about death, as well as the emotions and reactions of patients and family members. ${ }^{5}$

It is known that the nursing professional presents difficulties in living with the patient who experiences his or her finitude, by experiencing these conflicting feelings arising from unpreparedness in a potentiated manner, causing a distancing between the professional and the patient, as well as their families, the which does not fit humanized care. ${ }^{6}$

This hospital in its potential emphasizes the importance of making these professionals better prepared to cope with situations involving the care of these patients, as well as psychological support to deal with the situation of loss, frustration and death.

In view of the above, we proposed to carry out a study that answers the following guiding question: What are the perspectives experienced by nurses in the clinical management of chemotherapy in geriatric patients in an accredited hospital?

In this sense, it becomes important to describe the nurses with their own language as they are feeling and what experiences are having in this lived context. In the nurses' speeches of this study, their descriptions of the lived experience were sought to capture them in their subjectivity in the way they feel about the clinical management of chemotherapy in geriatric patients in an accredited hospital

This study is justified by revealing the experience of these nurses in regard to the many facets that permeate the oncological universe, empowering the nursing professional, so that he is sure of his daily practices, transcending the technical limits of care that the geriatric / cancer patient it raises. With these findings, permanent education processes that involve the nurse in the subject of death can be planned, reinforcing and broadening personal and professional reflection, regarding the improvement of care, responsibility and sensitivity to experience the nuances of cancer. 
However, this study aimed to describe the clinical management of chemotherapy in geriatric patients of a hospital accredited at the level of excellence in Brazil.

\section{Methods}

This is a descriptive, qualitative, experience-type study about the clinical management of chemotherapy in geriatric patients performed by Enfermeiros, prepared in the context of a private hospital accredited to excellence level in the city of João Pessoa (PB) ), Brazil, whose main objective is to describe the clinical management of chemotherapy in geriatric patients performed by nurses.

The methodological basis used in the activity was the Collective Health Nursing Practice Theory (TIPESC) that employs the dynamic systematization of capturing and interpreting a phenomenon articulated to the processes of social production and reproduction related to the health and illness of a given community, within the framework of its conjuncture and structure, within a historically determined social context. ${ }^{7}$

In this way, the capture of reality is characterized as the stage of knowledge of reality, which is an approximation and never a total knowledge of it, since it is dynamic and therefore there is a need to always be revisited. The knowledge of reality enables each discipline to define what is necessary to know at that moment, what can be worked by the Nurse during the period and what needs to be deepened in the period subsequent to the accomplishment of that practice. This type of study aims to approach the professional of the contracting institution where it provides health services, seeking the practical theory - practice relationship for a better problematization. ${ }^{8}$

The activities were carried out in an accredited private hospital in the sectors of the medical clinic, surgical hospitalization clinic and oncology department, in the daytime shifts, during the months of August and October 2018, by Nurses able to develop such practice, based on by the institution of origin, in their respective sectors of activity.

Thus, six (6) Nurses were involved in this activity using active observation and informal dialogues as apt and trained professionals, regarding the hierarchical primordial levels: Board, Management, Coordination and Assistants, during the months of reporting for the respective study, guided by a script built from the experience described. ${ }^{9}$

The topics covered were selected based on the demands made by the Nursing Assistants during the moments of reality capture, namely: "Nursing Assistance in Geriatric Oncology", "Clinical Management of Chemotherapy Performed by Nurses" and "Nurses' Performance in an Accredited Hospital at the Excellence Level in Brazil" (Table 1).

Table I Presentation of an exclusive nurse competence instrument

\section{Section I of relations with the person, family and collectively responsibilities and duties}

Art. 12 - Ensure to the person, family and community nursing assistance free of damage resulting from malpractice, negligence or recklessness.

Art. I3 - Carefully assess your technical, scientific, ethical and legal competence and only accept charges or assignments, when capable of safe performance for yourself and for others.

CONSIDERING the Law $n^{\circ} 7.498 / 86$ which regulates the practice of Nursing and provides other measures.

Art. I I -The Nurse performs all the nursing activities, being: I - privately: m) nursing care of a higher technical complexity and requiring scientifically based knowledge and the ability to make immediate decisions.

Art. 12 - The Nursing Technician performs a mid-level activity, involving orientation and follow-up of the Nursing work in auxiliary degree, and participation in the planning of Nursing care, being specially: $\S 1^{\circ}-$ Participate in the programming of nursing care; $\S 2^{\circ}-$ Perform Nursing care actions, except for those of the Nurse, in compliance with the provisions of the Sole Paragraph of the Art. II of this Law.

Art. 15 - The activities referred to in arts. 12 e 13 of this Law, when exercised in public and private health institutions and in health programs, may only be performed under the guidance and supervision of a Nurse. CONSIDERING Resolution COFEN N $210 / 1998$ which deals with the performance of nursing professionals working with antineoplastic chemotherapy.

Art. $I^{\circ}-$ To approve the Technical Norms for Individual, Collective and Environmental Biosafety of the procedures to be carried out by the Nursing professionals who work with antineoplastic chemotherapy, in the form of the annexed Regulation.

Item 4 - Competence of the nurse in antineoplastic chemotherapy: - To administer antineoplastic chemotherapy, according to the pharmacokinetics of the drug and therapeutic protocol

\section{Results and discussion}

\section{Nursing assistance in geriatric oncology}

The incidence of cancer grows in Brazil and the world at a pace that accompanies the aging population, due to the increase in life expectancy. The new social indicators published by the Brazilian Institute of Geography and Statistics (IBGE) point out that neoplasias have gained increasing importance in the mortality profile, occupying in Brazil the second place as cause of death. This change is due to the aging of the population, since according to the IBGE, in the period between 1999 and 2008, the Brazilian earned, on average, three more years of life and the current life expectancy is 73.5 years. ${ }^{10}$
Oncology and aging are related in a direct way, so the number of cancer cases increases proportionately to age, that is, the more the population grows older, the trend in the growth of the number of cancer cases is confirmed. They also emphasize that cancer has an enormous impact on geriatrics and gerontology all over the world and experiencing this reality involves rethinking the care and implementing new strategies aimed at the best care of this part of the population. Thus, there is an increase in the incidence of cancer in the elderly population, which is confirmed by INCA (2017) data, reporting that in Brazil $70 \%$ of cancer diagnoses occur in individuals over 60 years of age. , of this universe, approximately $60 \%$ are over 70 years old. ${ }^{10}$ 
Therefore, faced with this information, the elderly are perceived as a clientele that is increasingly present in the cancer treatment centers, which deserves a special look on health policies, with a view to promoting early detection and offering quality services. In addition, according to the Statute of the Elderly, Law N ${ }^{\circ} 10.741$, in $1^{\circ}$ in October of 2003, Title II, Fundamental Rights, Chapter IV, From the Right to Health, Art. 15, the integral health care of the elderly is ensured through the Unified Health System, guaranteeing the universal and equal, joint and continuous access of actions and services to the prevention, promotion, protection and recovery of health, including attention diseases that affect the elderly. ${ }^{11}$

\section{Clinical management of chemotherapy by nurses}

It is known that the work process focused mainly on the administration of antineoplastic medications and administrative activities compete with nurses, who dedicate most of the workday in bureaucratic activities such as release of reports for authorization of procedures of high complexity, request of tests that prove the patient's diagnosis, control of patients in the use of medicines released by the institution that provide services, management of personnel, materials of the sector, quality indicators (notification of extravasation and chemotherapy spillage, patient screening, cancellation of care, and complications, such as obstruction, infection, rupture and malocclusion), these activities are time-consuming, making direct patient care and evaluation of the patient time-limited. ${ }^{12}$

The lack of knowledge of patients about their health status and treatment, and consequently, lack of clarification on essential care to avoid complications during treatment. This type of approach is performed in the first care, completely effective, since the nurses in question are capable and able to perform this task.

The constant records of non-conformities in audits (internal and external) due to the documentation of the care provided and the guidelines given to the patients about their treatment, which are activities of the nurses, clarify the paths traced by the patient.

Also, compliance with article 8 of Administrative Rule no. 420 of August 2010, which establishes that the patient has the right to be informed about the drug to be applied, adverse effects and what to do in case of manifestation of possible adverse effects; These situations give rise to great concern for the nurses of the oncology geriatric patients sectors, since nurses have as their object of professional practice care for the cancer patient and we must provide a quality nursing assistance and in accordance with the current legislation. ${ }^{13}$

The Ordinance of the COFEN n ${ }^{\circ} 358 / 2009$ considers the Nursing Process (PE) as a methodological instrument that guides professional nursing care and documentation of professional practice, and its operationalization evidences the contribution of nursing in the health care of the population, increasing visibility and professional recognition. The EP involves what the nursing professional does (actions and nursing interventions), based on the judgment of specific human needs (nursing diagnoses), to achieve the results so that it is legally responsible (nursing results). ${ }^{14}$

With the Nursing Process, the improvement in the therapeutic control, effectiveness and efficiency in the adherence to the treatment for greater clarification on the disease and treatment, identification of aspects that demand nursing interventions, allows an improvement of the self-care, in addition to a decrease in the number hospitalization for complications. ${ }^{14}$
The stages of identification and elaboration of nursing diagnoses, results and interventions are of paramount importance for the operationalization of this process, in order to systematize care. For this, the professional must be technically prepared and have an interest in the human being and his way of life, based on the reflective awareness of his relations with the subject, the family and the community. ${ }^{15}$

The second stage of the nursing diagnosis is referred to as a process of reasoning understood as the nurses' way of thinking (judgments, interpretations, cognitive abilities, scientific knowledge and experience) about patient data; It is the basis for determining the nursing interventions, with which it aims to achieve the established results; It is related to their doing and to the quality of care dispensed, which is based on a complex intellectual activity of the nurse seeking the correct interpretation of the problems identified so that they can be solved through an effective care plan. ${ }^{16}$

In the scenario of chemotherapy treatment there are many possibilities of intervention of the nurse, besides the fact that the actions to be developed have as a focus the geriatric patient, the educational process can facilitate changes in the way of acting, through the acquisition of knowledge and skills for the management of these occurrences, since the lack of control of the adverse effects by the patients may be related to the lack of specific information offered during the treatment, contributing to the aggravation of the symptoms. ${ }^{17}$

Within the multidisciplinary team, the nurse is considered the communication link between other professionals and patients. It participates with technical and scientific knowledge and can develop an adequate and individualized therapeutic plan, providing a safe and effective treatment and assuring the necessary support and information during the treatment. ${ }^{18}$

In assisting the individual with cancer, nurses have a fundamental role in health education, for directing nursing care to the promotion, maintenance and restoration of health, prevention of illness, and to encourage the patient and family members to discuss the doubts that have arisen during the treatment. ${ }^{18}$

\section{Nurses' performance in an accredited hospital at the excellence level in Brazil}

The nurse, in the private hospital, develops managerial actions in favor of improvements in the care and quality of the service provided by the institution. At this rate, the actions undertaken by this professional require planning, decision making, monitoring and control of nursing actions, with a view to optimizing the resources that are dispensed. Nurses have the perception that the employer expects that the prescribed activities will not only be implemented in their effectiveness, but will also exceed their expectations.

Nurses understand that the expectation of the employer is that they are proactive and that they are always above expectations. This understanding corroborates the results of a study developed in an accredited hospital in the northeast of Brazil, where it was evidenced that the proactive management of nurses is considered an important strategic factor for organizational performance, since they act in the active and preventive control of adverse events that guarantee the effectiveness of the patient care and the optimization of resources. The perspectives indicate the division of labor, the rhythms, times and requirements that are required of the nurses of private hospitals. ${ }^{19}$ 
Such perspectives are in line with contemporary literature on the ways in which work is organized, in which it is evident that this situation imposes diverse demands on its workers, including cadences, speed, learning, information, adaptation to organizational expectations and market demands, characteristics of immaterial labor. Governed by such cadences, the ways of working and of being nurses of private hospitals, are clothed by ideals of the world of contemporary work..$^{20}$

In the hospital work, the nurse is constrained by contemporary ways of working, in which the specificities of his work are related to immaterial tasks, which require significant dedication, in a movement of body and soul delivery to the organization..$^{21}$

Developing the nursing process with aptitude in the accredited hospital in question is a facilitated task, in the sense that the company offers us the best for the development of the work. Acting in the service, in its different potential, allows us to always present the best.

Maintaining the quality of Nursing, while managers of the care of that particular sector is not an easy task, but it is also not impossible to achieve. With this scientific report, we would like to thank the company for the excellent working conditions, so that we can always offer the best for the patient and finally the entire management body, for allowing and believing in our study and scientific potential, as well as the care.

\section{Conclusion}

The experience made possible to the Nurses a new experience in the field of the contracting company, since it made possible the approach with the care process regarding oncology geriatrics, of a private institution accredited to excellence level, scenario not yet fully explored by the group. In this sense, it was possible to perceive the multiplicity of spaces and audiences that may be subject to educational interventions of this nature to problematize the work process.

This activity also contributed to the construction and improvement of nursing know-how in one of its work processes, the clinical management of chemotherapy by Nurses, teaching-learning, greatly enriching the formation of the egress profile of nurses. critical and emancipatory way, since it points out principles for the organization of an extended professional education, in order to consider the specificities of the different health care production units.

However, during the process, there were some difficulties, such as the short interval of time directed to the development of planning and intervention of actions; the demand for transportation to resources in the acquisition of materials necessary for the execution of the practices; and the absence of these resources in the desired actuation stage.

It is perceptive that the experience of nurses, faced with the experience of the clinical management of chemotherapy in geriatric patients allowed these professionals to see care as an inherent process of life, leading them to a reflection on their own finitude and perceiving themselves not impotent of terminality (or not), in the midst of these feelings, relying on religiosity, familiarity, to overcome suffering shared with being-care, and cultivating empathy as a mechanism for understanding the experience of the other while being- world.

Finally, treating the nurse's role in the field of oncology geriatrics, with the necessary resources, made the group aware of the importance of patient care and service delivery in the study development area, respect and eternal thanks for the service that has all the tools for our work.

\section{Acknowledgements}

None.

\section{Conflict of interest}

Author declares that there is no conflict of interest.

\section{References}

1. Rodrigues ALM, Nascimento DM, Sato EC, et al. Glioblastoma with Oligodendroglioma component (GBMO) in an adolescent: a case report. International Archives of Medicine. 2018;(11):17557682.

2. Santos FC, Camelo SHHH, Laus AM, et al. O enfermeiro que atua em unidades hospitalares oncológicas: perfil e capacitação profissional. Enfermería Global. 2015;38.

3. Sousa FH, Valenti EV, Hamaji MP, et al. The use of spikes protocol in cancer: an integrative review. International Archives of Medicine. 2017(10).

4. Souza MC, LinsDR, Saraiva CNR, et al. Risk factors related to falls in elderly: a reflective study. MOJ Gerontol Ger. 2018;93(4):131-132.

5. Agra G, Ferreira TMC, Oliveira DMN, et al. Neoplastic wounds: controlling pain, exudate, odor and bleeding. International Archives of Medicine.2017;(10).

6. Souza MC, Araújo HS, Silva TTSM, et al. Treatment of venous ulcer in the elderly: implications for nursing. MOJ Gerontol Ger. 2018;3(4):287-291.

7. Souza NR, Santos ICRV, Bushatsky M, et al. Performance Of Nurses In Radiotherapy Services. International Archives of Medicine. 2017;(10).

8. Carvalho E, Bollela VR. Agendamento eletrônico do paciente (AEP) como ferramenta de gestão dos ambulatórios de um serviço de referência terciária em saúde. Revista Eletrônica Gestão \& Saúde. 2015;6(2):1446-1462.

9. Medina AM, Leal AF, Zavaglia GO. A consulta de enfermagem como estratégia de cuidado ao cliente oncológico em tratamento radioterápico. Ciência Cuidado e Saúde. 2013;(7).

10. Silva JMC, Valente RPPS. Estratégias de autocuidado das pessoas com doença oncológica submetidas a quimioterapia/radioterapia e a sua relação com o conforto. Revista electrónica trimestral de Enfermería. 2015.

11. Souza RS, Simão DAS, Lima EDRP. Perfil sociodemográfico e clínico de pacientes atendidos em um serviço ambulatorial de quimioterapia paliativa em Belo Horizonte. Rev Min Enferm. 2012;16(1):38-47.

12. Leite JF, Dimenstein M, Paiva R, et al. Sentidos da Saúde numa perspectiva do Gênero: um estudo com homens da cidade de Natal/RN. Psicol Ciênc Prof. 2016;36(2):341-353. 
13. Araujo LHL, Baldotto CS, Zukin M, et al. Survival and prognostic factors in patients with non-small cell lung cancer treated in the private health care. Rev Bras Epidemiol. 2014;17(4):1001-1014.

14. Barbosa IR, Costa ICC, Pérez MMB, et al. As iniquidades sociais e as disparidades na mortalidade por câncer relativo ao gênero. Rev Ciênc Plural. 2015;1(2):79-86.

15. Ribeiro AA, Nardocci AC. Desigualdades socioeconômicas na incidência e mortalidade por câncer: revisão de estudos ecológicos, 1998-2008. Saúde Soc. 2013;22(3):878-891.

16. Suter TM, Ewer MS. Cancer drugs and the heart: importance and management. Eur Heart J. 2013;34(15):1102-1011.

17. Swain SM, Whaley FS, Ewer MS. Congestive heart failure in patients treated with doxorubicin: a retrospective analysis of three trials. Cancer. 2003;97(11):2869-2879.

18. Huddart RA, Norman A, Shahidi M, et al. Cardiovascular disease as a long-term complication of treatment for testicular cancer. $J$ Clin Oncol. 2003;21(8):1513-1523.
19. Burlá C, Py L. Palliative care: science and protection at the end of life. Cad Saúde Pública. 2014;30(6):1139-1141.

20. Alcantara LS, Sant'Anna JL, Souza MG. Illness and finitude: considerations about the interdisciplinary approach in the oncological Intensive Care Unit. Ciênc Saúde Coletiva. 2013;18(9):2507-2514.

21. Mendonça AC, Moreira MC, Carvalho V. Cancer palliative care in an intensive care unit: a scientific production study of nursing. Esc Anna Nery. 2012;16(4):817-823.

22. Santos DCL, Silva MM, Moreira MC, et al. Planejamento da assistência ao paciente em cuidados paliativos na terapia intensiva oncológica. Acta Paul Enferm. 2017;30(3):295-300. 